\title{
Need for Parental Control and Mediation in Food Advertising to Children: A Review of Previous Research
}

\author{
Pavleen Kaur*, Raghbir Singh \\ Guru Nanak Dev University Amritsar, India \\ *topavleen@yahoo.co.in
}

\begin{abstract}
Food advertising to children is recognised worldwide as contributing to obesity in children. Much of the research in this area has been carried out in US, UK and other developed countries that are fighting the obesity epidemic. The phenomenon is, however, not restricted to the developed world only, but is now trickling down to the developing countries, such as India. Therefore, it is pertinent that necessary measures are devised and implemented so that Indian children may not face the same situation. At present, when governmental regulations are less forthcoming and marketers are enjoying the potential offered by a huge and untapped market for western foods, it becomes imminent for the parents to intervene and protect their children from banal effects of food advertising. Therefore, the present paper seeks to review various studies conducted in this area to highlight the need for TV viewing mediation by parents in the Indian situation.
\end{abstract}

\section{Key Words: Parental Control, Mediation, Food Advertising, Children}

\section{Introduction}

Children constitute a distinct and valuable set of consumers such that marketers try to build strong linkages with them directly through advertisements. Children are found glued to TV sets for many hours each day (Gortmaker et al., 1996) and are exposed to thousands of commercials each year (George, 2003; Kunkel et al., 2004). On analysing the content of TV ads, researchers have revealed that a large number of food ads are aired on children's network as well as prime time television that children watch (Arnas, 2006; Harrison and Marske, 2005; Morgan et al., 2008; Stitt and Kunkel, 2008). A concern here is due to the reason that commercials for candies, snacks, sodas and sugared cereals are largely aired as compared to commercials for more healthy or nutritious foods (Kunkel and Gantz, 1992; Kunkel et al., 2004; Kelly et al., 2007). Sweetened breakfast cereals, candy, desserts, low-nutrient beverages, and salty snack foods, referred to as 'Big Five' foods are the most commonly advertised products to children and are also the items most frequently requested of parents (Cairns et al., 2009). Advertisers generally use appeals focussing on fun, fantasy and humour to build associations of children with brands, without actually stating out the nutritional aspects of these foods. More so, children popular cartoon characters and celebrities are featured in ads to endorse and promote these products. They are also very successful in persuading children to buy the advertised foods.

Television commercials and prime-time programmes have thus been identified to largely influence the types of food that children ask their parents to buy, the food that they buy themselves and consequently consume. Therefore, such high levels of exposure to food ads while watching television promote obesity at multiple levels. Firstly, television viewing itself promotes snacking. Secondly, food commercials aired in between also trigger the desire to take energy rich food. Thirdly, sedentary TV viewing reduces metabolism in children and fourthly, excessive TV viewing displaces time for other outdoor energy expending activities in children. Although a direct causal link between advertising exposure and obesity in children is debated, yet, the researchers largely agree that advertising does contribute to the problem.

Excessive weight in children is being witnessed throughout the world (WHO, 2000) and is often referred to as 'globesity'. Obesity levels have reached alarming/epidemical levels in USA, UK, Australia and Europe so much so that a host of actions are being taken to fight the problem. Nevertheless, the quantum of obese/overweight people is also rising in the developing world. Though, China, Fiji, Thailand, Malaysia, and Philippines are even ahead of India, yet, the proportion of overweight people is rising in India (Consumers International, 2008). Obesity levels, as observed in parts of India have increased from 7.4\% in 2002 (Kapil et al., 2002) to 22.0\% in 2007 (Sharma, Sharma and Mathur, 2007). Obesity is a serious threat to children's health as it often leads to increased incidence of heart diseases, stroke, Type II diabetes, and poor oral health in children. For India, Yach, Stuckler and Brownell (2006) estimated that 
Type II diabetes would rise by $134 \%$ in India as compared to $36.5 \%$ in US and $76.5 \%$ in China. Owing to the seriousness of the issue, some systematic reviews have also been carried out by previous researchers independently or commissioned by bodies like OFCOM, WHO, etc. to minutely investigate this issue (for details see Hastings et al. 2003; Livingstone and Helsper, 2004; Scragg et al., 2006; Cairns et al., 2009).

Besides other factors (mainly genetic), targeting children through advertising is identified to contribute to obesity. It is pertinent to note, in this respect, the factors which are specific to India. Income levels in India are rising particularly due to the increase in the number of dual career families. Rising education levels contribute to delayed marriages and children are born into "time poor" families, where affordability of food is not a problem. The parents themselves are tech savvy, and so do not hesitate to let out their children to tech savvy products as television, computers, home theatres etc. So, television steps into the life of children by acting as an 'electronic babysitter' for them. Children watch a lot of television in the pre-school years itself. As their association with the television builds up, they get more informed about new products, prices, features etc., such that they assist family purchases or make independent purchases for the family (Soni and Singh, 2003). Food/grocery purchases specifically are made by them independently or heavily influenced by them. As they grow older, they even spend out of their own pocket money. In such a situation, marketers focus on children while framing food messages and target them to promote foods (which are largely considered energy dense and unhealthy). Parents are the first party to bear the brunt of advertising influence. They face a large number of product requests which are difficult to honour (Buijzen and Valkenburg, 2005). More so, they are also concerned about the health of their children. So, the situation entails that necessary steps must be taken to protect children from ubiquitous food advertising as it contributes to obesity and leads to serious health problems in them.

In the background of the foregoing discussion, the present paper seeks to revisit some of the studies already conducted in the context of effects of food advertising on children and the nature of parental mediation desired as can mitigating the negative effects of exposure of children to food ads. It is further sought to bring out some of the research issues that must be addressed by future research in India.

\section{Literature Review}

A review of previous studied related to parental concerns and mediation of TV viewing, type of mediation, effect of communication and other related variables on mediation is presented in this section.

Parental mediation of children's food and TV viewing: Parents are seen to be especially interested in promoting good nutrition habits for their children (Gillespie, 1989). Therefore, they mediate and control the type of products/brands that children can buy. Berey and Pollay (1968) noted that parents generally act as intermediary purchasing agents for the child. They found that the mother played a "gatekeeper" role and bought cereals that weighed strongly on nutrition. In cases of disagreement with the child over brand decisions, the mother tried to superimpose her preferences over those of the child. Chan and McNeal (2003) in a study of Chinese parents also reported that parents exhibited strict control over the kinds of products that children can or cannot buy. Fiates et al. (2008) found that parental control over children's food choices was exercised by, a) simply not buying what children wanted, b) buying but restricting access to them at home, c) trying to educate, negotiate or force children, or, d) appealing to children for health reasons. Apart from gatekeeping of foods that children can/cannot buy, parents also take mealtime actions to prevent overweight in children. Hendy et al. (2009) showed that parents set snack limits, ensure daily fruits and vegetables availability and use fat reduction actions during meals to ensure consumption of nutritious foods by their children.

Strict parental control over children's diets may however be impossible as increased exposure to food ads on television may build a strong preference/desire (may be hedonic) for advertised unhealthy foods. Frequent denials by parents may then be impossible and also result into parent-child conflict. Therefore, it is imperative that parents also mediate children's TV viewing to reduce exposure to food ads. Parental mediation of food advertising to children on TV is largely under-researched. Researchers have assessed occurrence of TV mediation, generally, in home settings (Bijmolt et al. 1998; Valkenburg et al. 1999; Buijzen and Valkenburg, 2003; Barkin et al., 2006). They have found that parental mediation moderates parent-child conflict (Buijzen and Valkenburg, 2003, 2005). When parents try to mediate TV viewing they commonly indulge in active mediation or restrictive mediation. Active mediation refers to discussion of media content with children which may include the positive or negative aspects of media. Restrictive mediation refers to control of content or frequency of TV viewing. Some parents also indulge in 'co- 
viewing' which means watching TV with children (Nathanson, 2001). However, this may not be used as a mediation strategy by parents always. Parents are able to reduce negative consequences of exposure to ads by active mediation as discussing program content with children helps the child to evaluate the program and stimulates children to learn more from TV (Wiman, 1983; Bijmolt, Classen and Brus, 1998; Valkenburg et al., 1999; Buijzen and Valkenburg, 2003, 2005). It is also noted to increase children's comprehension of advertising (Buijzen and Valkenburg, 2005). On the other hand, parents who resort to restrictive mediation tend to reduce the time children spend viewing TV (Van den Bulck and Van den Bergh, 2000). It has also been found that a high level of control of TV viewing (restrictive mediation) is seen to result in lower understanding of TV advertising (Bijmolt et al., 1998). Jordan et al. (2006) found that a majority of parents (59\%) used multiple mediation approaches in order to reduce children's TV viewing time. Their study revealed that both instructive (active) and restrictive mediation approaches had positive associations with increased awareness about negative media effects. They mostly used content restrictions, or placed time restrictions, while only a small proportion of parents restricted access to TV by not putting a TV in the child's bedroom. Some other strategies such as linking TV viewing to desired behaviour of the children were also reported to be used by nearly half of the parents.

As regards mediation of food ads, Buijzen (2009) in a diary study of 234 parents of 4 to 12 year old children in Netherlands investigated how different styles of advertising mediation (active vs. restrictive) moderated the relation between children's advertising exposure and their consumption of advertised energy dense food products. It was found that active mediation was considerably more effective in reducing advertising effects than restrictive mediation in younger (4-8 years old) as well as older children (9-12 years old). However, among younger children, restrictive mediation was also effective in reducing the relation between advertising and food consumption. Therefore, it was concluded that with critical and open discussion about advertising and control and rule making about consumption, parents can reduce the impact of food advertising on children's energy-dense food consumption. Restrictions of advertising exposure were effective among preschool and early elementary school children, but not among the older children.

Mediation by parents varies across families according to attitude towards advertising, nature of communication and parenting styles in families. Wiman (1983) explored the role of parental interaction and control of TV viewing on children's responses. He found that mothers who held more negative attitude towards advertising exercised stricter controls on their child's TV viewing behaviour. Their children also exhibited better understanding of the purpose and nature of advertising and made fewer purchase requests. These mothers were able to create an atmosphere for a child which was conducive to learning about advertising, more critical of commercials and so discouraged purchase requests. Rose, Bush, and Kahle (1998) also confirmed similarly. On comparing US and Japanese mothers, they found that American mothers held more negative attitude towards both advertising in general and children's advertising in particular, and kept close control of the children's viewing habits as compared to their Japanese counterparts. Mukherji (2005), on comparing the means of Indian, American, and Japanese mothers (from Rose et al.'s (1998) study) found that Indian mothers had the least negative attitudes toward television advertising as well as children's advertising. They also had least control over their children's television viewing of the three groups of mothers and had more discussions with their children than her Japanese counterparts. The positive attitudes of Indian mothers toward television advertising was attributed to the fact that ads were associated with fulfilling utilitarian roles in informing and educating the viewer about new product offerings.

The impact of nature of communication in families on mediation of TV food advertising was investigated by Buijzen, Bomhof and Schuurman (2008). They found that consumption related communication (more particularly socio-related communication) was considerably effective in reducing the effect of advertising exposure on consumption. However, more research is needed to investigate the role of communication in mitigating the negative effects of food advertising on children.

As regards effect of parenting styles on mediation methods used by parents, Carlson (1998) found that authoritative mothers, who are both restrictive and warm, are more likely to support parental responsibility to mediate effects of TV on children. Carlson and Grossbart (1988) reported that parents are getting more permissive and authoritative in their parenting styles. These findings were further corroborated by 0' Dougherty, Story and Stang (2006) who observed that when parents do not honour purchase requests while co-shopping with their children, the refusal strategy includes saying a soft "no" or a non-verbal "no", ignoring, walking away or telling the child they do not need the food item. 


\section{Other factors affecting parental mediation of TV advertising}

Mothers have been seen to be primary care givers to children and thus associated with mediation of TV viewing and mothers' reports have, therefore, been generally taken. Choice of a mediation strategy is seen to vary across some demographic variables. For example, highly educated parents are more likely to restrict TV viewing (Wiman, 1983; Valkenburg et al., 1999, Nathanson, 2001). Parents with younger children are seen to mediate more as compared to parents of older children (Valkenburg et al., 1999; Barkin et al., 2006). Parents have been reported to use instructive mediation more often with younger children (Barkin et al., 2006; Jordan et al., 2006). Parental concerns about the effects of media exposure affect the amount and style of mediation they use. Boys and girls have been reported to perceive and react differently to similar patterns of parental guidance (Van den Bulck and Van den Bergh, 2000). High socioeconomic status is also associated with higher mediation (Wiman, 1983).

In addition to demographics, parents' nutrition knowledge is also seen to be related to use of TV during meals. Coon et al. (2001) found that parents who are high on nutrition knowledge and perceive food ads to promote consumption of unhealthy foods, do not use TV during meals. While parents who prefer ready to eat meals/pre-prepared meals or food brought from outside, that is, score low on nutrition knowledge do not mind if TV is on during meals.

In order to mitigate the negative effects of foods promotion through TV advertising, it is essential that parents have sufficient time to interact with children. Another associated condition is that the parents feel the need to indulge in active/restrictive mediation or co-view children to make them understand the purpose and intent of ads. Jordan et al. (2006) found that although parents felt that reducing TV time would have a positive impact, yet, they either did not perceive the need to restrict TV viewing or felt that watching TV is fun, relaxing, family activity or keeps children safely occupied while parents complete their chores. In a study by Fiates et al. (2008) also, children felt that their parents did not control the number of hours spent on TV viewing. Verma and Larson (2002), in a study in India, also noted that watching TV by youth is typically a family activity, occurring in a context in which parents' supervision and influence is likely and where co-viewing happens to reduce daily stress experienced by family members.

\section{Discussion}

Marketers spend huge sums while advertising foods to children. Instead of seeking a direct, short term response from children whereby food advertising leads to purchase and consumption, marketers use a gamut of practices (advertising and other forms of promotion) to influence food choices permanently. Such attempts affect lifestyles, habits, peer norms, food perceptions, familial decisions and cultural expectations (Livingstone, 2005). Pingali (2006) purports that food demand in Asia is getting increasingly westernised and adoption of this pattern of diets is reported to promote obesity in developing countries (BBC, 2000). Children are more vulnerable for they may not be as sophisticated consumers in developing countries as their western counterparts since advertising focussed at them is a relatively new phenomenon. The impact of creative elements in advertising on attitude of children remains largely unexplored in India (Kaur and Singh, 2006). Still, marketers use the same degree of sophistication in reaching them (Witkowski, 2007).

Parents have been found to express concerns about children's advertising (Carlson and Grossbart, 1988), quality of foods advertised (Burr and Burr, 1976) and advertising of unhealthy foods when children watch TV (Morley et al., 2008). A vast majority of parents are in favour of a reduction of the number of advertisements during children's broadcasts. Parents support that foods advertising to children should be strongly regulated and that the government should introduce stronger restrictions on food advertising at times when children watch television (Morley et al., 2008). There is, however, too little regulation controlling the programme to advertising ratio especially during children's programmes in developing countries including India (Consumers International, 2004). Though there are codes for advertisers, set up by Advertising Council of India (ASCI), yet, strict enforcement of them is less forthcoming and self regulation is the norm for the industry. Consumers' International report (2008) concludes that self regulation pledges by industry players are only 'confusing' as they are implemented without giving adequate nutritional information to parents. 
Such a situation, in which children do not understand the intent of commercials or deception in advertising, and get swayed by the appeals used to target them, lead us to questions such as-"who should take up the responsibility of protecting children?" and "how this objective can be achieved?". India, which presents tremendous opportunities to the entire world today shall face obesity epidemic, much like the developed world as it treads on the progress trajectory, if timely action is not taken. When media literacy programmes for children, government legislations and enforcement, and self restraint exercised by food marketing companies are inadequate; the parents need to take up the responsibility of mediating the effects of influence of ads on their children on their children. This is all the more relevant for the fact that parents are most interested in good health and well being of their children. Thus, they need to devote time to children's activities. The joint/extended family system in India also provides great support in supervising children and modifying their media habits. Grandparents can share quality time with children, can cook their favourite foods and serve as effective caregivers to children, thus reducing the burden on time-poor parents. At least in tier II cities, towns and villages, food habits are still largely traditional that are influenced more by local cultures as compared to the western culture. The situation can be brought under control more easily as Verma and Larson (2002) report that Indian adolescents spend less than two hours watching television. For the same reason, possibly, Fiates et al. (2008) also found in Brazil, which is fast developing like India, that TV viewing does not stop children from indulging in physically active pursuits. This presents considerable opportunities for controlling the situation and preventing future generation of India from turning obese and disease prone. Research investigating these issues needs more attention of researchers in India. Therefore, future research in India must specifically focus on

- Level of awareness and concern in parents about media content directed at children.

- The extent of independent TV viewing allowed to children.

- Patterns of interaction between parents and children and nature of communication in families in light of the fact that though the proportion of nuclear families is rising in India (particularly in metro cities), still, a large proportion of families continue to be joint/extended families whereby, extension in family is generally sought for meeting childcare requirements (Ram and Wong, 1994).

- The perceived need for mediation as recognised by parents. Also, other barriers to mediation like lack of time, less involvement in child's activities etc.

- Parents' attitude towards nutrition content of advertised foods, their own food preferences and concerns to maintain healthful diets for their children.

\section{References}

Arnas, Y. A. (2006). The Effects of Television Food Advertisement on Children's Food Purchasing Requests. Pediatrics International (2006) 48, 138-145.

Barkin, S., Edward, I. P., Richardson, I., Klinepeter, S., Finch, S. \& Krcmar, M. (2006), Parental Media Mediation Styles for Children Aged 2 to 11 Years. Arch Pediatr Adolesc Med., 160, 395-401.

BBC (2000). West exports obesity to developing world. BBC News Online, September 26 (Available at: http://news.bbc.co.uk/1/hi/health/943783.stm).

Berey, L. A. \& Polay, R. W. (1968). The Influencing Role of Child in Family Decision-Making. Journal of Marketing Research, 5, 70- 72.

Bijmolt, T. H. A., Claassen, W. \& Brus, B. (1998). Children's Understanding of TV Advertising: Effects of Age, Gender and Parental Influence. Journal of Consumer Policy, 21, 171-194.

Buijzen, M. (2009). The Effectiveness of Parental Communication in Modifying the Relation between Food Advertising and Children's Consumption Behaviour. British Journal of Developmental Psychology, $27,105-121$.

Buijzen, M. \& Valkenburg, P. M. (2005). Parental Mediation of Undesired Advertising Effects. Journal of Broadcasting \& Electronic Media, 49, 153-165.

Buijzen, M., Bomhof, E. and Schuurman, J. (2008). Explaining the Link between Television Viewing and Childhood Obesity: A Test of Three Alternative Hypotheses. Journal of Children and Media, 2, 6774.

Buijzen, M., Schuurman, J., \& Bomhof. E. (2008).Associations between Children's Television Advertising Exposure and their Food Consumption Patterns: A Household Diary-Survey Study. Appetite, 50, 231-239.

Buijzen, M. \& Valkenburg, P.M. (2003). The Effects of Television Advertising on Materialism, Parent-Child 
Conflict, and Unhappiness: A Review of Research. Applied Developmental Psychology. 24, 437-456.

Burr, P.L. \& Burr, R. M. (1976). Television Advertising to Children: What Parents are saying about Government control. Journal of Advertising, 5(4), 37-41.

Cairns, G., Angus, K. \& Hastings, G. (2009). The Extent, Nature, and Effects of Food Promotion to Children: A Review of the Evidence to December 2008, A Report prepared for WHO.

Carlson, L. (1998). Mothers' Preferences for regulating children's Television. Journal of Advertising, (Available at: www.allbusiness.com).

Carlson, L. \& Grossbart, S. (1988). Parental Style and Consumer Socialization of Children. Journal of Consumer Research, 15, 77-94.

Chan, K. \& McNeal, J. U. (2003). Parent-Child Communication about Consumption and Advertising in China. Journal of Consumer Marketing, 20(4), 317-334.

Consumers International (2004). The Junk Food Generation-A multi-country survey of the influence of television advertisements on children, (Available at: epicpolicy.org/.../the-junk-food-generationa-multi-country-surveyinfluence-television-advertisements-chil).

Consumers International (2008). The Junk Food Trap, Marketing Unhealthy food to Children in Asia Pacific, (Available at: www.consumersinternational.org).

Coon, K. A., Goldberg, J., Rogers, B. L. \& Tucker, K. L. (2001). Relationships between Use of Television during Meals and Children's Consumption Patterns. Pediatrics, 107(1), E7.

Fiates, G. M. R., Amboni, R. D. M. C. \& Teixeira, E. (2008). Television Use and Food Choices of Children: Qualitative Approach. Appetite, 50, 12-18.

Filiatrault, P. and Ritchie, J. R. B. (1980). Joint Purchasing Decisions: A Comparison of Influence Structure in Family and Couple Decision-Making Units. Journal of Consumer Research, 7, 131-140.

George, A. (2003). Your 'T.V. Baby, Ad Man's Delight. (http://www.hindu.com/thehindu/mp/2003/12/22/stories/2003122201400200.htm).

Gillespie, A. H. (1989). Comparison of Family Interaction Patterns Related to Food and Nutrition. Journal of the American Dietetic Association, 89, 509-512.

Gortmaker, S. L., Must, A., Sobol, A. M., Peterson, K., Colditz, G. A. \& Dietz, W. H. (1996). Television Viewing as a Cause of Increasing Obesity among Children in the United States, 1986-1990. Arch Pediatr Adolesc Med., 150, 356-362.

Harrison K. \& Marske, A. L. (2005). Nutritional Content of Foods Advertised During the Television Programs Children Watch Most. American Journal of Public Health, 95(9), 1568-1574.

Hastings, G., Stead, M., McDermott, L., Alasdair, F., MacKintosh, A. M., Rayner, M., Godfrey, C., Caraher, M. \& Angus, K. (2003). Review of the research on the effects of food promotion to children. (Final report): Food Standards Agency.

Hendy, M. H., Williams, K. E., Camise, T. S., Eckham, N. \& Hedeman, A. (2009). The Parent Mealtime Action Scale (PMAS). Development and Association with Children's Diet and Weight. Appetite, 52, 328339.

Jordan, A. B., Hersey, J. C., Judith A. M., \& Hetzler, C. D. (2006). Reducing Children's Television Viewing Time: A Qualitative Study of Parents and their Children. Paediatrics, 118, 1303-1310.

Kapil, U., Singh, P., Pathak, P., Dwivedi, S. N., \& Bhasin, S. (2002). Prevalence of Obesity among Affluent Adolescent School Children in Delhi. Indian Pediatrics, 39, 449-452.

Kaur, P. \& Singh, R. (2006). Children in Family Purchase Decision Making in India and the West-A Review. Academy of Marketing Science Review, 10(8), 1-32.

Kelly, B., Smith, B., King, L., Flood V., \& Bauman, A. (2007). Television Food Advertising to Children: The Extent and Nature of Exposure. Public Health Nutrition, 10(11), 1234-1240.

Kunkel, D. \& Gantz, W. (1992). Children's Television Advertising in the Multi-Channel Environment. Journal of Communication, 42(3), 134-152.

Kunkel, D., Wilcox, B. L., Cantor, J., Palmer, E., Linn, S., \& Dowrick, P. (2004). Psychological Issues in the Increasing Commercialization of Childhood. Report of the APA Task Force on Advertising and Children.

Livingstone, S. (2005). Assessing the Research Base for the Policy Debate over the Effects of Food Advertising to Children. International Journal of Advertising, 24(3), 273-296.

Livingstone, S. \& Helsper, E. (2004). Advertising Foods to Children: Understanding Promotion in the Context of Children's Daily Lives, A review of the literature prepared for the Research Department of the Office of Communications (OFCOM).

Matheson, D. M., Killen, J. D., Wang, Y., Varady, A., \& Robinson, T. N. (2004). Children's Food Consumption during Television Viewing. American Journal of Clinical Nutrition, 79, 1088-94.

Morgan, M., Fairchild, R., Phillips, A., Stewart, K. \& Hunter, L. (2008). A Content Analysis of Children's Television Advertising: Focus on Food and Oral Health. Public Health Nutrition, 12(6), 748-755 
Morley, B., Chapman, K., Mehta, K., King, L., Swinburn, B. \& Wakefield, M. (2008). Parental Awareness and Attitudes about Food advertising to Children on Australian Television. Australian and New Zealand Journal of Public Health, 32(4), 341-347.

Mukherji, J. (2005). Maternal Communication Patterns, Advertising Attitudes and Mediation Behaviours in Urban India. Journal of Marketing Communications, 11(4), 247-262.

Nathanson, A. I. (2001). Parent and Child Perspectives on the Presence and Meaning of Parental Television Mediation. Journal of Broadcasting \& Electronic Media, 45, 201-220.

O'Dougherty, M., Story, M. and Stang, J. (2006). Observations of Parent-Child Co-shoppers in Supermarkets: Children's Involvement in Food Selections, Parental Yielding, and Refusal Strategies. Journal of Nutrition Education Behaviour, 38, 183-188.

Pingali, P. (2006). Westernisation of Asian Diets and Transformation of Food Systems: Implications for Research and Policy. Food Policy, 32, 281-298.

Ram, M. \& Wong, R. (1994). Covariates of Household Extension in Rural India: Change over Time. Journal of Marriage and Family, 56(4), 853-864.

Rose, G. M., Bush, V. D. \& Kahle, L. (1998). The Influence of Family Communication Patterns on Parental Reactions towards Advertising: A Cross Nations Examinations. Journal of Advertising, 27(4), 7185.

Scragg, R., Quigley, R. \& Taylor, R. (2006). Does TV contribute to increased body weight and obesity in children? A report prepared by the scientific committee of the Agencies for Nutrition Action Wellington: Agencies for Nutrition Action.

Sharma, A., Sharma, K. \& Mathur, K. P. (2007). Growth Pattern and Prevalence of Obesity in Affluent Schoolchildren of Delhi. Public Health Nutrition, 10(5), 485-491.

Soni P. \& Singh, R. (2003). Dimensions of Purchase Decision Making in Families Revisited: Pitfalls and Prospects. The Management Review, 15(3), 59-88.

Stitt, C. \& Kunkel, D. (2008). Food Advertising during Children's Television Programming on Broadcast and Cable Channels. Health Communication, 23, 573-584.

Valkenburg, P. M., Krcmar, M., Peeters, A. L. \& Marseille, N. M. (1999). Developing a Scale to Assess Three Styles of Television Mediation: Instructive Mediation, Restrictive Mediation, and Social Coviewing. Journal of Broadcasting \& Electronic Media, 43, 52-66.

Van den B. J. \& Van den B. B. (2000). The Influence of Perceived Parental Guidance Patterns on Children's Media Use: Gender Differences and Media Displacement. Journal of Broadcasting \& Electronic Media, 44, 329-348.

Verma, S. \& Larson, R. W. (2002). Television in Indian Adolescents' Lives: A Member of the Family. Journal of Youth and Adolescence, 31(3), 177-183.

Wiman, A. R. (1983). Parental Influence and Children's Responses to Television Advertising. Journal of Advertising, 12, 12-18.

Witkowski, T. H. (2007). Food Marketing and Obesity in Developing Countries: Analysis, Ethics and Public Policy. Journal of Macromarketing, 27(2), 126-137.

World Health Organization (2000). Turning the Tide of Malnutrition: Responding to the challenge of the 21st century. WHO/NHD/00.7. Geneva, Switzerland.

Yach, D., Stuckler, D. \& Brownell, K. D. (2006). Epidemiologic and Economic Consequences of the Global Epidemics of Obesity and Diabetes. Nat. Med. 12, 62-66. 